\title{
Crescimento de Plantas de Café em Solos com Resíduos de PICLORAM $^{1}$
}

\author{
Development of Coffee Plants in Soils with Picloram Residues
}

D’ANTONINO, L. ${ }^{2}$, FRANÇA, A.C. ${ }^{3}$, SILVA, A.A. ${ }^{4}$ e FERREIRA, L.R. ${ }^{4}$ e SILVA, G.R. ${ }^{5}$

\begin{abstract}
RESUMO - Avaliou-se neste trabalho o crescimento de plantas de café cultivadas em um Latossolo Vermelho-Amarelo, com diferentes valores de $\mathrm{pH}$ e contaminado com resíduos de picloram. O experimento foi instalado em esquema fatorial $(2 \times 9)$, sendo o primeiro fator dois tipos de solo (Latossolo Vermelho-Amarelo $\mathrm{pH} 4,4$ e pH 6,2) e o segundo, nove doses de picloram $\left(0,20,40,60,80,100,120,140\right.$ e $\left.160 \mathrm{~g}^{2} \mathrm{a}^{1}\right)$, no delineamento de blocos casualizados, com quatro repetições. Aos 60 e 120 dias após aplicação do herbicida (DAP), procedeu-se à avaliação visual de intoxicação das plantas, área foliar, pelo método não destrutivo, do diâmetro do caule, por paquímetro, e da altura das plantas, bem como à contagem do número de folhas completamente expandidas. Aos 120 DAP, fez-se a determinação da massa da matéria seca da parte aérea, do caule e das raízes, além do comprimento das raízes e volume radicular. Concluiu-se que plantas de café recém-transplantadas em solos com resíduos do picloram têm redução no seu crescimento, o que pode ter reflexo na futura produtividade da cultura. Caso sejam feitas operações visando ao aumento do $\mathrm{pH}$ desses solos, aumenta-se o risco da ocorrência de carryover.
\end{abstract}

Palavras-chave: carryover, herbicida, cultivos sucessivos, Coffea arabica.

\begin{abstract}
This work aimed to evaluate the growth of coffee plants cultivated in an Oxisol with different $p H$ values and contaminated with picloram residues. The experiment was a factorial $(2 \times 9)$, with the first factor consisting of two types of soil (Oxisol pH 4.4 and $p H$ 6.2) and the second factor, nine doses of picloram (0,20,40,60,80,100,120, 140 and $\left.160 \mathrm{~g} \mathrm{ha}^{-1}\right)$, arranged in a randomized block design with four replications. At 60 and 120 days after herbicide application (DAP), a visual evaluation was carried out of intoxication of the plants, leaf area, by a non-destructive method; stem diameter by caliper and plant height, as well as counting the number of fully-expanded leaves. At 120 DAP, determination of dry mass of the leaves, stem and roots was carried out, besides root length and root volume. It was concluded that coffee plants recently transplanted into soil with residues of picloram have a growth reduction that may affect future crop productivity. Operations aiming at increasing the $\mathrm{pH}$ of these soils increase the risk of carryover.
\end{abstract}

Keywords: carryover, herbicide, successive crops, Coffea arabica.

\section{INTRODUÇÃO}

O preço do café é influenciado por demanda e procura, cotação do dólar e turbulências econômicas. No Brasil, na época de preços mais atrativos é comum pecuaristas migrarem para a atividade cafeícola. Ao transformar áreas de exploração agropecuária em cafezais, ocorrem com frequência problemas de intoxicação das mudas de café recém-transplantadas com herbicidas usados nas pastagens. Além disso,

Recebido para publicação em 13.4.2011 e aprovado em 27.10.2011.

2 Engo-Agrọ D.Sc., Dep. de Fitotecnia, Universidade Federal de Viçosa - DFT/UFV, <leonardo@ufv.br>; ${ }^{3}$ D.Sc., D.Sc., Professor Adjunto, Dep. de Agronomia, Universidade Federal dos Vales do Jequitinhonha e Mucuri - UFVJM; ${ }^{4}$ D.Sc., Professor Associado, DFT/UFV; ${ }^{5}$ Mestrando, DFT/UFV. 
pode-se contaminar o solo com a adubação orgânica procedente de área do solo de pastagens tratadas com herbicidas auxínicos (Rodrigues \& Almeida, 2005).

Entre os herbicidas de maior uso em pastagem do Brasil, destaca-se a mistura (picloram $+2,4-\mathrm{D}$ ), a qual se caracteriza pela eficiência no controle de plantas daninhas dicotiledôneas e seletividade para as forrageiras gramíneas. Todavia, o picloram apresenta elevada persistência no solo, com meiavida variando de 20 a 300 dias, o que pode afetar negativamente culturas sucessoras às pastagens (Souza et al., 2001; Close et al., 2003b; Thill, 2003; Berisford et al., 2006; Santos et al., 2006). Além dessa característica, o picloram possui baixa sorção aos coloides do solo, alta solubilidade em água e elevado potencial de lixiviação (D’Antonino et al., 2009b), podendo atingir facilmente aquíferos subterrâneos (Bovey \& Richardson, 1991; Pang et al., 2000; Close et al., 2003a). Berisford et al. (2006) relatam que o picloram tem alta mobilidade lateral e vertical, além de alta persistência em solos argilosos. Por conseguinte, D'Antonino et al. (2009a) reportam que as condições climáticas alteram de modo decisivo o comportamento desse herbicida no solo.

Baixas concentrações no solo de herbicidas auxínicos, como o picloram, podem causar intoxicação em espécies sensíveis, como soja, feijão, algodão e outras dicotiledôneas, quando cultivadas em sequência (Silva et al., 2007), bem como em mudas de café. Além disso, se ocorrer deriva de aplicações mal conduzidas de auxinas, estas podem causar sérios danos ao crescimento de culturas dicotiledôneas (Kelley et al., 2005), como cucurbitáceas, solanáceas, entre outras.

Segundo Bovey et al. (1982), a persistência de herbicidas no solo pode variar de alguns meses a mais de três anos, dependendo do produto, da dose utilizada, do solo e do clima. Santos et al. (2006) verificaram resíduos até 360 dias após a aplicação de herbicidas à base de picloram em solo de textura argiloarenosa.

Entre as características do solo que influenciam o comportamento dos herbicidas de caráter iônico aos coloides orgânicos e minerais, destaca-se o pH do solo. Alterações no $\mathrm{pH}$ do solo altera o estado de ionização das moléculas de herbicidas iônicos, como o picloram, influenciando a adsorção dos mesmos aos coloides orgânicos e minerais (Silva et al., 2007). Em consequência disso, a degradação, a persistência e, principalmente, a atividade do herbicida são afetadas pelo $\mathrm{pH}$ do solo, pois menor quantidade de produto poderá estar disponivel a absorção pelas raízes das plantas (Bailey \& White, 1970; Locke \& Bryson, 1997). Pode-se também afirmar que o picloram apresenta alto potencial de lixiviação em Argissolo Vermelho-Amarelo e em Latossolo Vermelho-Amarelo e que o pH desses solos foi determinante na sua movimentação (D'Antonino et al., 2009b). Assim, acredita-se que a calagem pode vir a alterar de modo significativo a disponibilidade do picloram no solo, influenciando diretamente em sua eficiência de controle das plantas daninhas, persistência e potencial de acumulação em águas subterrâneas.

Considerando o problema exposto anteriormente, a grande utilização do picloram em pastagens e a substituição de áreas de pastagens por lavouras cafeícolas, realizou-se este trabalho com o objetivo de avaliar o crescimento de mudas recém-transplantadas de café em solos contaminados com resíduos de picloram.

\section{MATERIAL E MÉTODOS}

O experimento foi realizado no período de maio a novembro de 2008, utilizando-se amostras de um Latossolo Vermelho-Amarelo coletadas em área não cultivada e sem histórico de aplicação de herbicidas, cujas características físicas e químicas estão descritas na Tabela 1. Após a coleta da amostra do solo, esta foi dividida em duas subamostras, que foram armazenadas em caixas plásticas de 1.000 L. Numa das subamostras, procedeuse à aplicação de calcário dolomítico (PRNT $=80 \%$ ), visando elevar a saturação por bases a 60\% (Guimarães et al., 1999), permanecendo em repouso por 60 dias. Após esse período, avaliou-se o $\mathrm{pH}$ da subamostra que recebeu calcário, o qual foi corrigido para 6,2; em seguida, procedeu-se à adubação de todas as subamostras, na proporção de $1,0 \mathrm{~kg}$ de superfosfato simples para 100,0 L de solo. 
Tabela 1 - Caracterização física, química e classificação textural das amostras de solo utilizadas no experimento. Viçosa-MG

\begin{tabular}{|c|c|c|c|c|c|c|c|c|c|c|}
\hline \multicolumn{11}{|c|}{ Análise granulométrica } \\
\hline \multicolumn{2}{|l|}{ Solo } & Argila & Silte & \multicolumn{2}{|r|}{ Areia } & \multicolumn{5}{|c|}{ Classificação textural } \\
\hline LVA & \multicolumn{2}{|r|}{51} & 4 & \multicolumn{2}{|r|}{46} & \multicolumn{5}{|c|}{ Argiloarenoso } \\
\hline \multicolumn{11}{|c|}{ Análise química } \\
\hline \multirow{2}{*}{ Solo } & $\mathrm{pH}$ & $\mathrm{P}$ & $\mathrm{K}^{+}$ & $\mathrm{Ca}^{++}$ & $\mathrm{Mg}^{++}$ & $\mathrm{H}+\mathrm{Al}$ & CTC total & V & $\mathrm{m}$ & $\mathrm{MO}$ \\
\hline & $\left(\mathrm{H}_{2} \mathrm{O}\right)$ & \multicolumn{6}{|c|}{$\left(\mathrm{cmol}_{\mathrm{c}} \mathrm{dm}^{-3}\right)$} & \multicolumn{2}{|c|}{$(\%)$} & $\left(\right.$ dag kg $\left.^{-1}\right)$ \\
\hline Original $^{1 /}$ & 4,4 & 2,9 & 52 & 1,2 & 0,5 & 6,27 & 8,19 & 37 & 24 & 2,8 \\
\hline 1 & 4,4 & 128,3 & 24 & 4,9 & 0,3 & 7,26 & 12,52 & 42 & 12 & 1,6 \\
\hline 2 & 6,2 & 118,1 & 44 & 7,7 & 0,9 & 0,17 & 8,88 & 98 & 0 & 1,4 \\
\hline
\end{tabular}

1/ Solo Original: amostra do LVA no momento da coleta; Solos 1 e 2: amostras do solo coletadas nos vasos ao final do experimento, sendo Solo 1 sem e Solo 2 com aplicação de calcário.

Posteriormente, preencheram-se vasos previamente impermeabilizados com filme de polietileno com 12,0 L do substrato. O experimento foi instalado em blocos casualizados, com quatro repetições no esquema fatorial $(2 \times 9)$, sendo o primeiro fator dois tipos de solo (Latossolo Vermelho-Amarelo, pH 4,4 e pH 6,2) e o segundo, nove doses de picloram. A aplicação do picloram nas doses de $0,20,40,60,80,100,120,140$ e $160 \mathrm{~g}^{\text {ha }}{ }^{-1}$ foi feita na superfície do solo nos vasos, utilizando-se um pulverizador costal pressurizado a $\mathrm{CO}_{2}$, equipado com barra de dois bicos TT 11002, com volume de calda de $150 \mathrm{~L} \mathrm{ha}^{-2}$. Oito horas após a aplicação do herbicida, procedeu-se ao plantio de uma muda de café, cultivar Mundo Novo (IAC 379/ 19), proveniente de sacolas plásticas, com quatro a cinco pares de folhas desenvolvidas e em bom estádio vegetativo.

As irrigações das plantas nos vasos foram realizadas sempre que necessário, visando manter a umidade do solo próxima à capacidade de campo. Aos 30 dias após o plantio, realizou-se adubação de cobertura com $30 \mathrm{~g}$ de cloreto de potássio e $5 \mathrm{~g}$ de sulfato de amônio por vaso (Guimarães et al., 1999). Para caracterizar a homogeneidade das mudas, procedeu-se a uma avaliação, no dia do plantio delas (0 DAP), da característica área foliar, realizada de acordo com o método não destrutivo proposto por Antunes et al. (2008). Foi também medido o diâmetro do coleto, utilizando-se paquímetro graduado em milimetros, bem como a altura das plantas, medindo-se do solo até o último par de folhas completamente expandidas do ramo ortotrópico, além da contagem do número de folhas completamente expandidas. Aos 60 e 120 DAP, efetuaram-se as mesmas avaliações anteriormente citadas, com o objetivo de avaliar o crescimento acumulado nessas épocas. Também aos 60 e 120 DAP, foi realizada avaliação visual de intoxicação das plantas, adotando-se escala de 0 a 100, em que 0 indica ausência de sintomas de intoxicação e 100 a morte das plantas.

Aos 120 DAP, as plantas foram seccionadas rente ao solo, sendo separadas em folhas, caule e raizes. Nas raizes das plantas, determinou-se o comprimento $(\mathrm{cm})$ e a densidade radicular, medida pela razão entre matéria fresca das raízes e volume de água deslocado $\left(\mathrm{g} \mathrm{mL}^{-1}\right)$. Depois disso, as plantas de café foram colocadas em estufa de circulação forçada de ar $\left( \pm 65^{\circ} \mathrm{C}\right)$, até atingirem massa constante, visando à determinação da matéria seca de raízes, caules e folhas.

No final do experimento, após a retirada das plantas dos recipientes plásticos, foram coletadas amostras dos solos destes, procedendo-se em seguida a nova caracterização química (Tabela 1).

Para interpretação dos dados, empregouse a análise de variância, utilizando-se o teste $\mathrm{F}(\mathrm{p} \leq 0,05)$. Efetuou-se o desdobramento da interação significativa, empregando-se a análise de regressão para as doses de picloram nos dois pHs de solo, com escolha dos modelos 
baseada na sua significância, no fenômeno biológico e no coeficiente de determinação $\left(R^{2}=\right.$ S.Q. Reg./S.Q. Trat.).

\section{RESULTADOS E DISCUSSÃO}

A presença de resíduos do picloram em ambos os solos causou sintomas de intoxicação visíveis nas plantas de café aos 60 e 120 dias após o plantio (DAP), sendo com maior intensidade nas plantas cultivadas no LVA pH 6,2 (Figura 1A, B). Nestes, aos 60 DAP, ocorreu intoxicação acima de $50 \%$, a partir de doses aplicadas iguais ou superiores a $100 \mathrm{~g} \mathrm{ha}^{-1}$, de picloram; já as plantas cultivadas no LVA pH 4,4 só atingiram esse patamar de sintomas na presença de doses em torno de $160 \mathrm{~g} \mathrm{ha}^{-1}$ (Figura 1A). Por conseguinte, na avaliação realizada aos 120 DAP (Figura 1B), ocorreu intoxicação de $58,75 \%$ nas plantas de café no LVA pH 4,4, na dose de $160 \mathrm{~g} \mathrm{ha}^{-1}$, e de $56,25 \%$ no LVA pH 6,2, na dose de $80 \mathrm{~g} \mathrm{ha}^{-1}$.

De acordo com Mersie \& Foy (1985) e Oliveira et al. (2001), a sorção máxima de vários herbicidas ocorre em valores de $\mathrm{pH}$ próximos de seu pKa. Isso indica que maiores quantidades do picloram estavam presentes na solução do solo no ambiente com $\mathrm{pH}$ mais elevado $(6,2)$, havendo menor sorção do herbicida aos coloides orgânicos e minerais. O contrário ocorreu no LVA pH 4,4, o qual apresentou maior sorção do picloram, pois esse valor de $\mathrm{pH}$ é mais próximo ao $\mathrm{pKa}(4,1)$ do herbicida, o qual é de 2,3 (Rodrigues \& Almeida, 2005). Silva et al. (2007) destacam que os herbicidas podem apresentar natureza iônica ou não iônica, sendo o picloram herbicida iônico - considerado um ácido fraco. O estado de ionização das moléculas dos herbicidas influencia sua sorção aos coloides orgânicos e minerais do solo, que por sua vez afeta a degradação, a persistência e, principalmente, a sua atividade. Isso ocorre porque menor quantidade de herbicida poderá estar disponível para absorção pelas raízes das plantas (Ferri et al., 2000).

A Figura 1A, B evidencia que ao longo do tempo (avaliações realizadas aos 60 e 120 DAP) não ocorreu recuperação das plantas intoxicadas, significando que a metabolização do xenobiótico no solo é lenta, conforme rela- tado por Santos et al. (2006). Esses autores constataram atividade desse herbicida até 366 dias após a sua aplicação em solo de textura argiloarenosa, $\mathrm{pH}$ 5,5. Em consequência da intoxicação, as plantas de café acumularam menor quantidade de matéria seca nas raízes (Figura 2). Nas plantas cultivadas no LVA pH 4,4, houve queda de $66,3 \%$ na matéria seca das raízes das plantas que cresceram no solo com resíduos de 160 $\mathrm{g}$ ha ${ }^{-1}$, em comparação ao solo sem aplicação.

Observa-se na Figura 2 que as plantas toleraram melhor o picloram nesse solo até a dose de $60 \mathrm{~g} \mathrm{ha}^{-1}$, com decréscimo de 2,3\% na matéria seca das raízes em relação ao tratamento sem aplicação. A partir de resíduos no solo de $80 \mathrm{~g} \mathrm{ha}^{-1}$, houve decréscimo na matéria
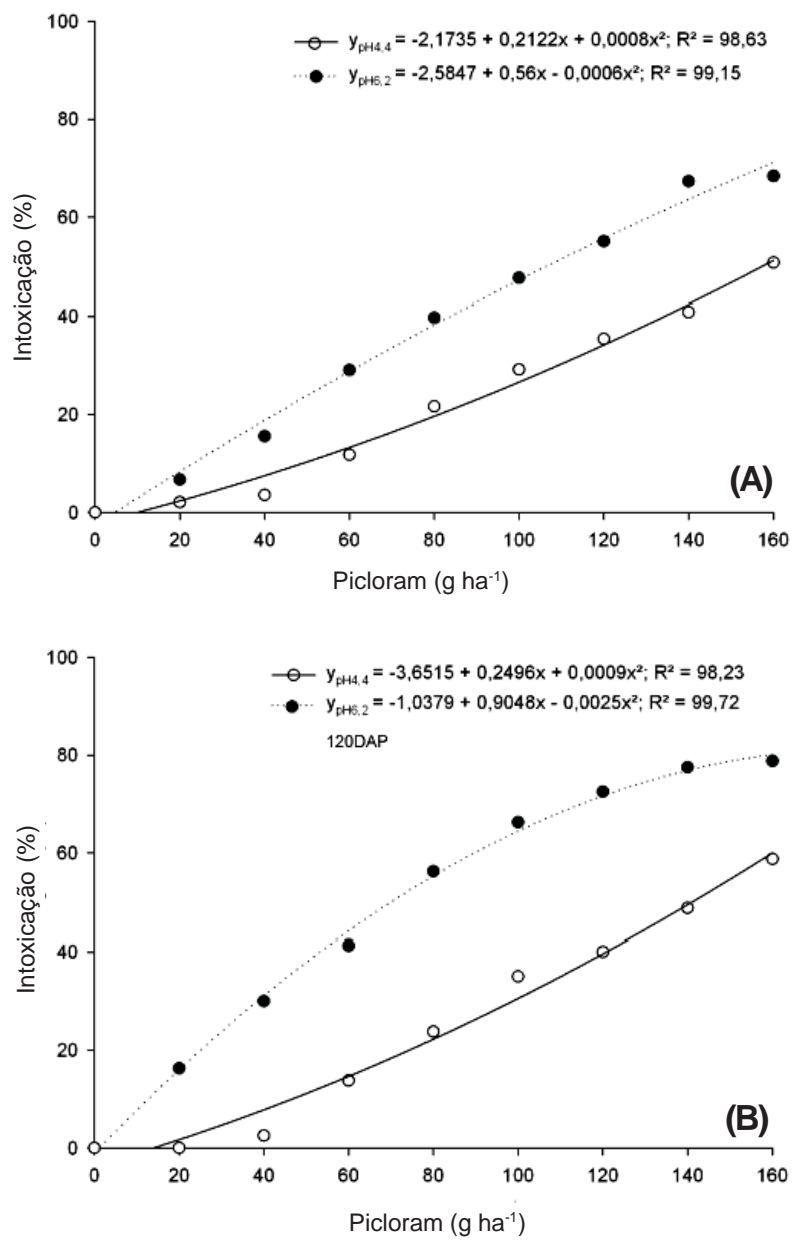

Figura 1 - Intoxicação de plantas de café cultivadas em solos tratados com diferentes doses de picloram, aos 60 (A) e 120 (B) dias após a aplicação. 


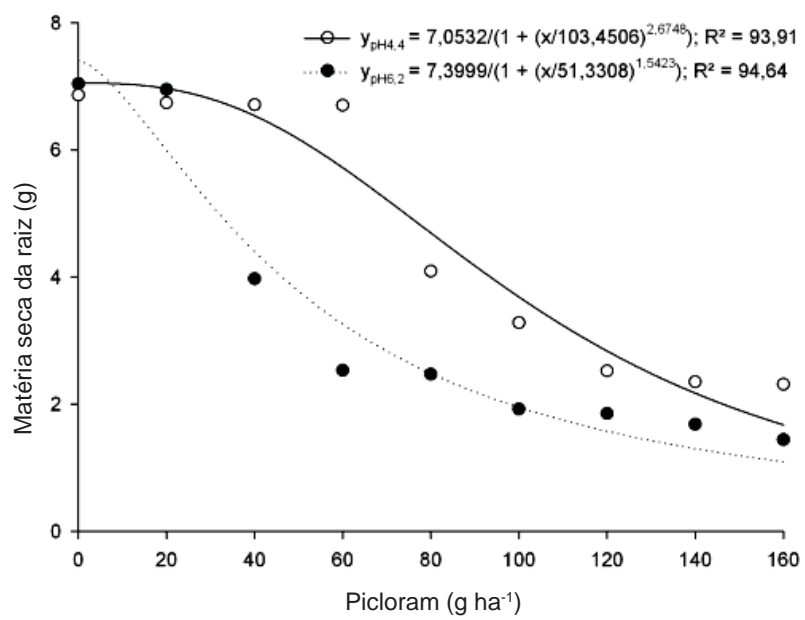

Figura 2 - Acúmulo de matéria seca em raízes de plantas de café cultivadas em solos tratados com diferentes doses de picloram.

seca das raízes de 40,4\%, em comparação com o solo sem resíduos. No caso das plantas de café cultivadas no LVA pH 6,2 (Figura 2), houve redução de $79,5 \%$ no acúmulo de matéria seca das raízes quando se comparou o tratamento sem aplicação do picloram ao tratamento com aplicação de $160 \mathrm{~g} \mathrm{ha}^{-1}$. Houve redução de 43,6\% na matéria seca das raízes das plantas de café crescendo em ambiente com resíduos de picloram em torno de $40 \mathrm{~g} \mathrm{ha}^{-1}$, quando em comparação ao tratamento sem aplicação do xenobiótico. Segundo Thill (2003), plantas tratadas com auxinas têm perda de rigidez das paredes celulares devido ao incremento na síntese da enzima celulase, principalmente nas raízes, causando em pouco tempo a destruição desse órgão vital.

A menor tolerância das mudas de café ao picloram observada quando estas foram cultivadas em solo LVA pH 6,2, em relação às cultivadas no LVA pH 4,4, pode ser atribuída à maior disponibilidade do herbicida no solo para a absorção pelas plantas. Desse modo, o substrato com menor quantidade de resíduos do picloram poderia ter maior concentração deste na solução do solo. Os resultados obtidos estão em concordância com Assis (2009), o qual relata haver menor sorção do picloram num LVA pH 6,33 em comparação a um PVA pH 4,96, estando o fenômeno diretamente

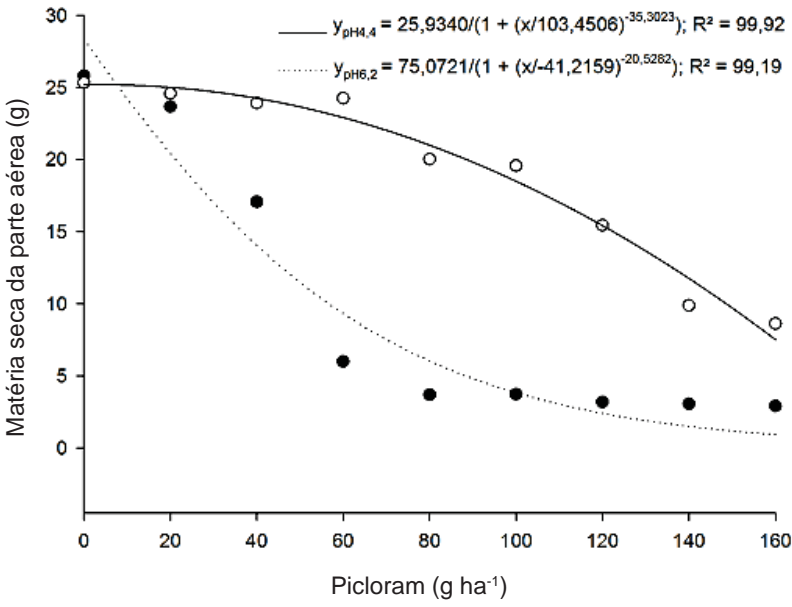

Figura 3 - Acúmulo de matéria seca da parte aérea de plantas de café cultivadas em solos tratados com diferentes doses de picloram.

ligado ao $\mathrm{pH}$ do solo e aos teores de matéria orgânica.

A presença de resíduos de picloram nos solos causou maior queda no acúmulo de matéria seca da parte aérea das plantas de café no solo com pH 6,2 (Figura 3). Dessa forma, as plantas conduzidas no LVA pH 4,4 acumularam $69,7 \%$ menos matéria seca com a aplicação de $160 \mathrm{~g} \mathrm{ha}^{-1}$ de picloram quando comparadas às do solo sem aplicação. As maiores reduções no acúmulo de matéria seca são observadas a partir da aplicação de $80 \mathrm{~g} \mathrm{ha}^{-1}$, em que se verifica redução de $27,7 \%$, em relação ao tratamento sem aplicação desse herbicida. No entanto, com a aplicação de $160 \mathrm{~g} \mathrm{ha}^{-1}$ de picloram no solo com pH 6,33, a queda no acúmulo de matéria seca das plantas de café foi de $88,9 \%$, quando em comparação ao tratamento sem aplicação do herbicida. Aplicações de 20, 40, 60 e $80 \mathrm{~g} \mathrm{ha}^{-1}$ do picloram neste solo causaram reduções no acúmulo de matéria seca das plantas de café de 9,21; 40,$89 ; 76,44$; e $85,66 \%$, respectivamente. Isso faz pensar que, no solo com maior $\mathrm{pH}$ $(6,2)$, maior quantidade do herbicida estava disponivel para absorção radicular, o que aconteceu devido à maior quantidade de moléculas ionizadas nesta faixa de $\mathrm{pH}$, no caso do picloram - herbicida classificado como ácido fraco. Um ambiente com $\mathrm{pH} \mathrm{6,2,} \mathrm{superior} \mathrm{ao}$ pKa do composto, fez com que o herbicida se ionizasse, apresentando cargas negativas, fazendo com que houvesse repulsão pelas argilas 
e pela fração orgânica do solo (Silva et al., 2007).

Herbicidas auxinicos induzem o fechamento estomático e, em muitos casos, provocam distúrbios na atividade fotossintética e respiração, provocados pelas alterações do balanço iônico nas células (Pemadasa \& Jeyaseelan, 1976), diminuindo sobremaneira as taxas de crescimento das plantas. Estudos sugerem que o metabolismo de ácidos nucleicos e os aspectos metabólicos da plasticidade da parede celular são seriamente afetados. Acredita-se que esses produtos interfiram na ação da enzima RNA-polimerase e, consequentemente, na síntese de ácidos nucleicos e proteínas (Thill, 2003).

Em consequência dos efeitos desses herbicidas, verifica-se crescimento desorganizado, que leva essas espécies a sofrer, rapidamente, epinastia das folhas, retorcimento do caule, engrossamento das gemas terminais e morte da planta, em poucos dias ou semanas (Silva et al., 2007).

Observa-se, na Figura 4A, B, aumento do diâmetro do caule das plantas de café na região do coleto. Maiores diâmetros são verificados nas plantas que vegetaram no solo com maior $\mathrm{pH}$, pois, provavelmente, o picloram estava em maior concentração na solução desse solo. De acordo com Silva et al. (2007), auxinas induzem, em espécies não seletivas, intensa proliferação celular em tecidos, o que causa a interrupção do floema, impedindo o movimento dos fotoassimilados das folhas ao sistema radicular. Contudo, esses sintomas de intoxicação causados pelo picloram não são detectados em gramíneas, pois estas têm o arranjamento do tecido vascular em feixes dispersos, sendo estes protegidos pelo esclerênquima. Essa característica especial das monocotiledôneas pode prevenir a destruição do floema pelo crescimento desorganizado das células, causada pela ação de herbicidas auxínicos.

Seguindo a tendência dos parâmetros anteriormente discutidos, foram observados maiores efeitos com menores doses do picloram no solo com pH 6,2, em comparação ao solo com pH 4,4. Esse efeito causou maior decréscimo no acúmulo de matéria seca do
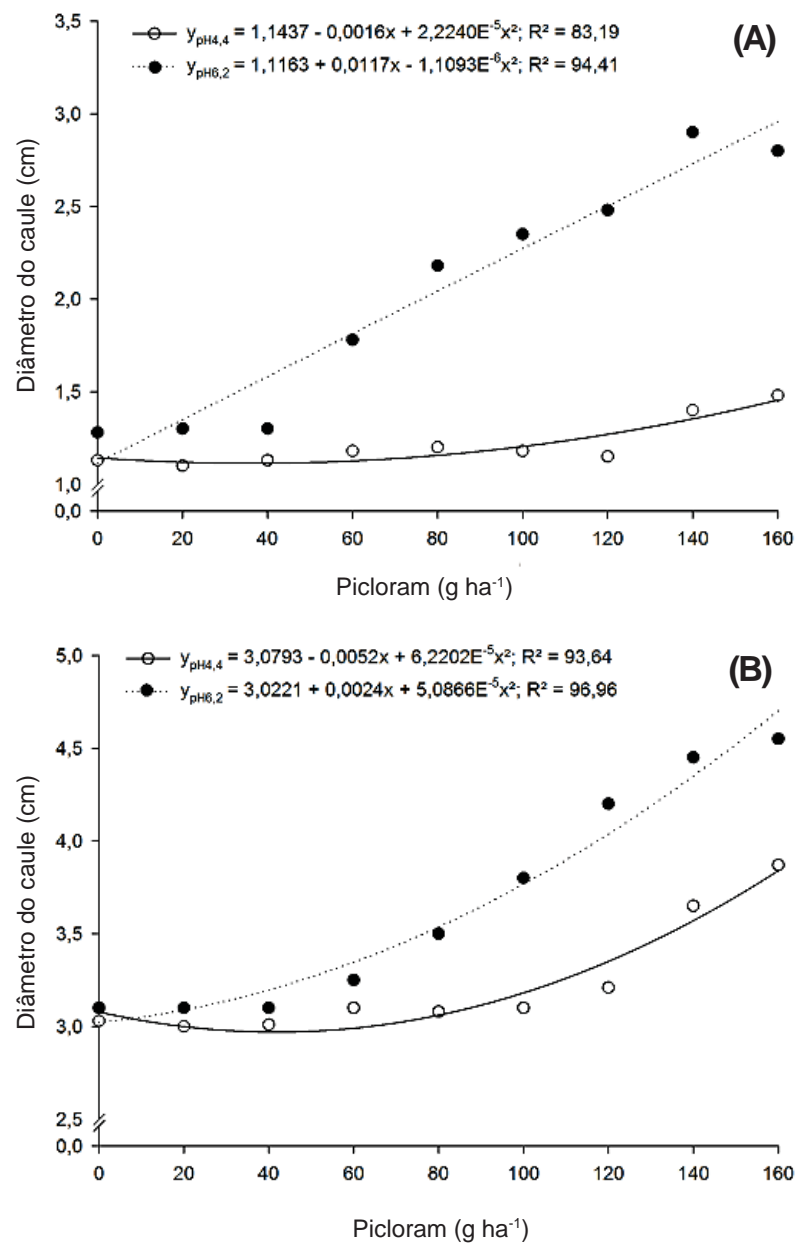

Figura 4 - Diâmetro do caule de plantas de café cultivadas em solos tratados com diferentes doses de picloram, aos 60 (A) e 120 (B) dias após a aplicação.

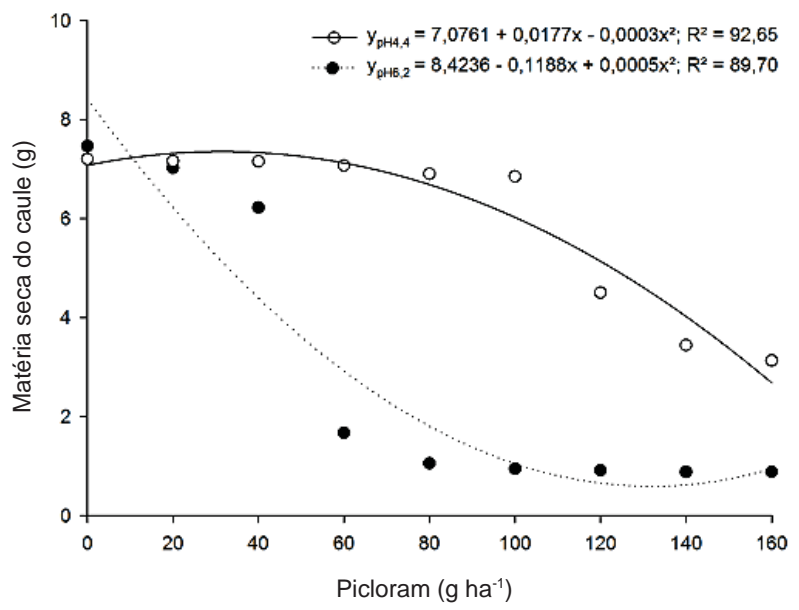

Figura 5 - Acúmulo de matéria seca no caule de plantas de café cultivadas em solos tratados com diferentes doses de picloram. 


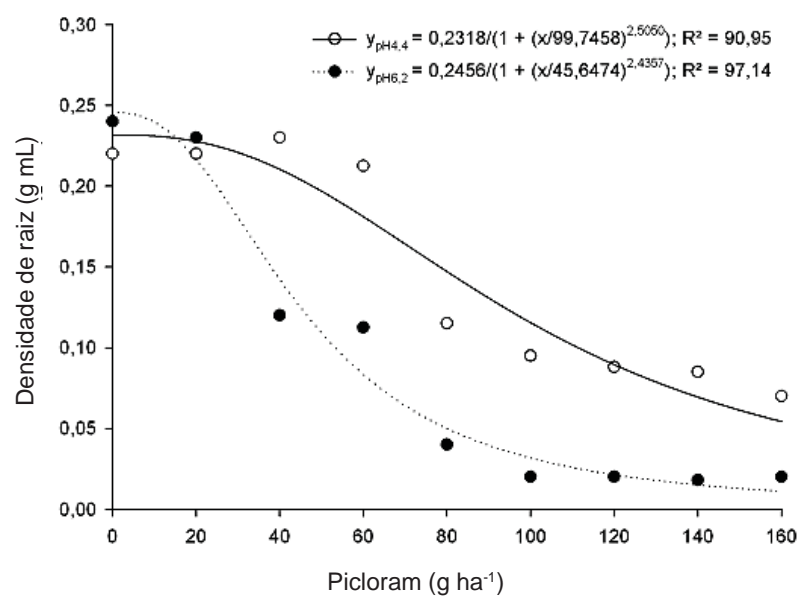

Figura 6 - Densidade de raízes de plantas de café cultivadas em solos tratados com diferentes doses de picloram.

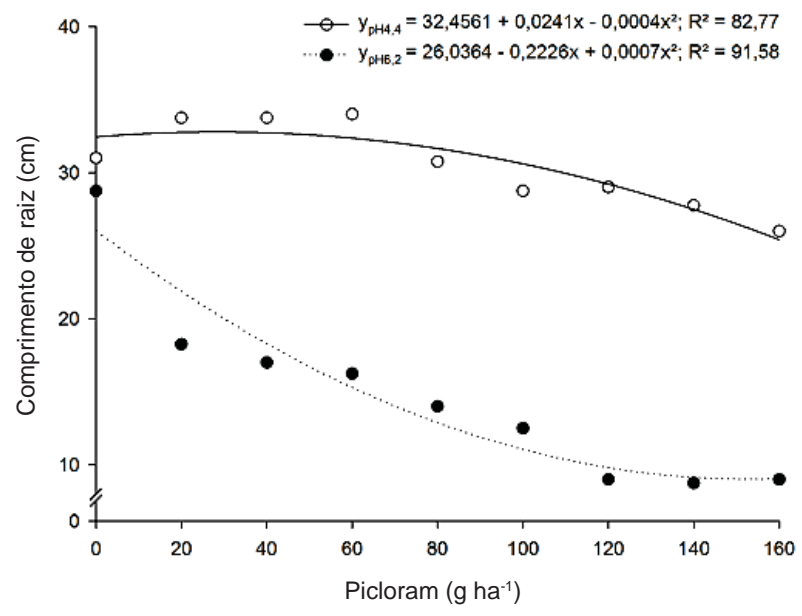

Figura 7 - Comprimento de raízes de plantas de café cultivadas em solos tratados com diferentes doses de picloram.

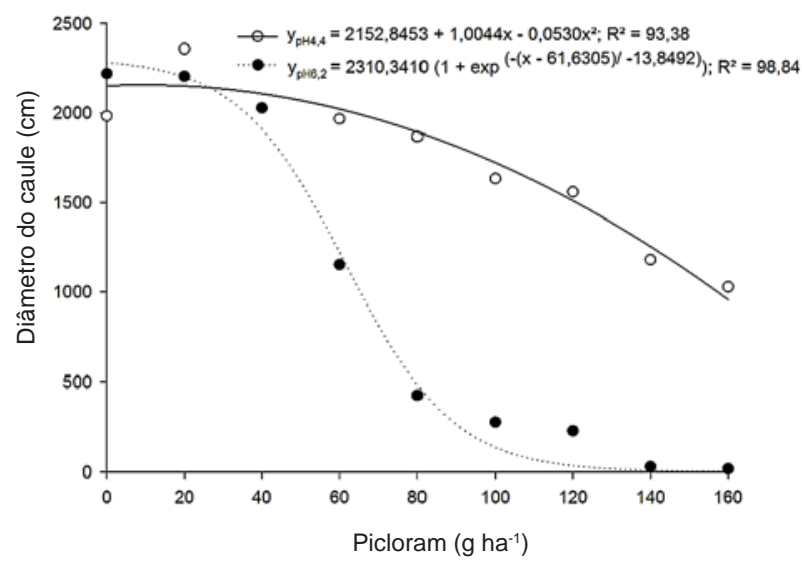

Figura 8 - Área foliar de plantas de café cultivadas em solos tratados com diferentes doses de picloram.
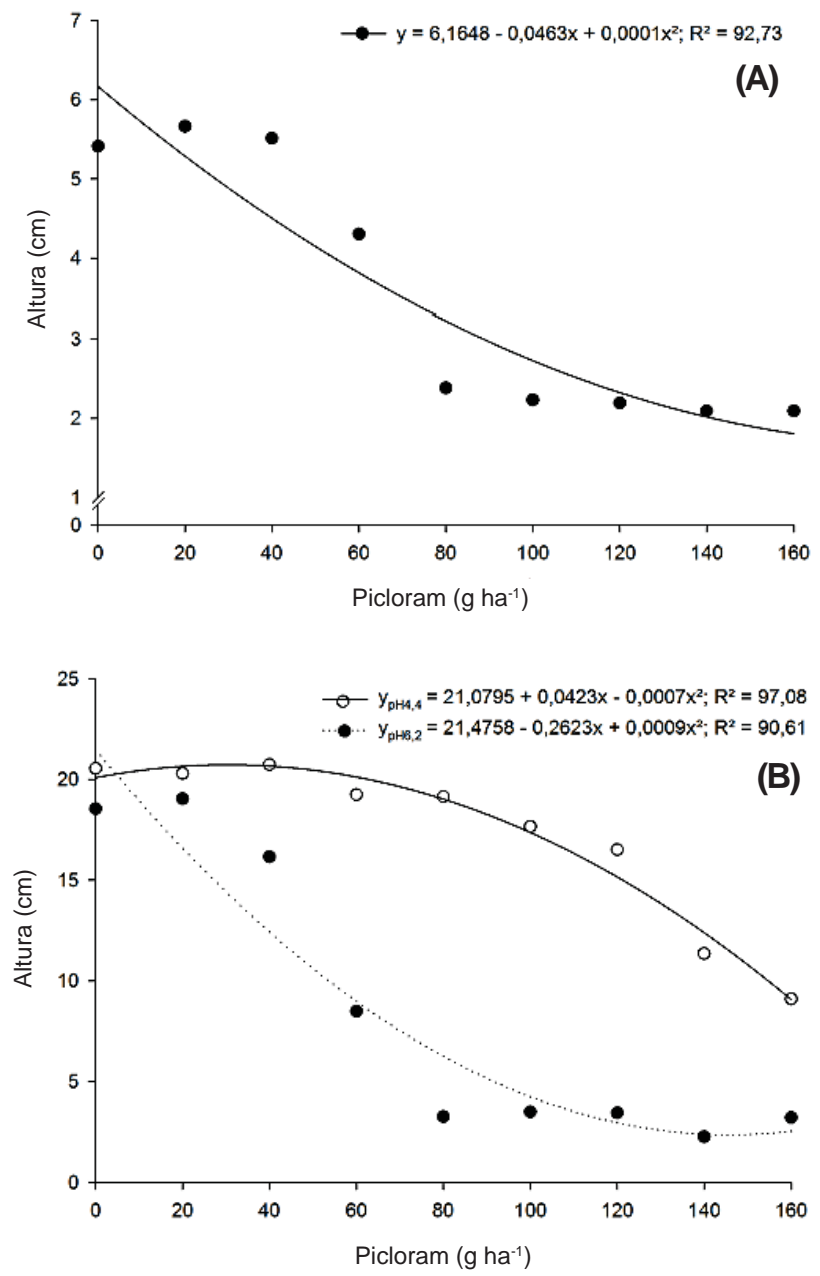

Figura 9 - Altura de plantas de café cultivadas em solos tratados com diferentes doses de picloram, aos 60 (A) e 120 (B) dias após a aplicação.

caule das plantas de café cultivadas no solo com pH 6,2 (Figura 5). Além dessa variável, o mesmo fenômeno se repete para densidade e comprimento de raízes (Figuras 6 e 7), área foliar (Figura 8) e altura de plantas (Figura 9A, B).

Faz-se a ressalva de que, aos 60 DAP, não houve diferença na altura de plantas entre os dois solos. Esse fato pode estar ligado à pequena velocidade de ação do picloram puro. De acordo com Silva et al. (2007), esse herbicida, na planta, apresenta efeito lento, porém extremamente persistente (a planta não consegue metabolizar rapidamente o picloram). A mistura 2,4-D + picloram, muito utilizada em pastagens no controle de plantas daninhas perenes, 
apresenta a vantagem de ter efeito mais rápido, em comparação com o uso do picloram isolado.

Pode-se afirmar que plantas de café recém-transplantadas, em solos com histórico recente de uso do picloram, podem ter redução no seu crescimento, com reflexos futuros na sua produtividade. Assim, o estabelecimento de lavouras de café nessas áreas deve ser feito com cautela, pois há risco de intoxicação às plantas caso seja feita a calagem desses solos. Em solos com maiores pHs, o risco de carryover aumenta sobremaneira em função da menor sorção do herbicida ao solo, comprometendo a viabilidade dos cafeeiros.

\section{LITERATURA CITADA}

ANTUNES, W. C. et al. Allometric models for non-destructive leaf area estimation in coffee (Coffea arabica and Coffea canephora). Ann. Appl. Biol., v. 153, n. 1, p. 33-40, 2008.

ASSIS, E. C. Sorção, dessorção e lixiviação do picloram em solos brasileiros. 2009. 81 f. Dissertação (Mestrado em Agroquímica) - Universidade Federal de Viçosa, Viçosa, MG, 2009.

BAILEY, G. W.; WHITE, J. L. Factors influencing the adsorption, desorption and movement of pesticides in soil. Residue Rev., v. 32, n. 1, p. 29-92, 1970.

BERISFORD, Y. C. et al. Leaching and persistence of herbicides for kudzu (Pueraria montana) control on pine regeneration sites. Weed Sci., v. 54, n. 2, p. 391-400, 2006.

BOVEY, R. W.; MEYER, R. E.; HEIN JR., H. Soil persistence of tebuthiuron in the Claypan Resource Area of Texas. Weed Sci., v. 30, n. 2, p. 140-144, 1982.

BOVEY, R. W.; RICHARDSON, C. W. Dissipation of clopyralid and picloram in soil and seep flow in the blacklands of Texas. J. Environ. Qual., v. 20, n. 3, p. 528-531, 1991.

CLOSE, M. E. et al. Field study of pesticide leaching in an allophonic soil in New Zealand. 1: Experimental results.

Austr. J. Soil Res., v. 41, p. 809-824, $2003 a$.

CLOSE, M. E. et al. Field study of pesticide leaching in an allophonic soil in New Zealand. 1: Experimental results.

Austr. J. Soil Res., v. 41, p. 825-846, 2003b.

D’ANTONINO, L. et al. Efeitos de culturas na persistência de herbicidas auxínicos no solo. Planta Daninha, v. 27, n. 2, p. 371-378, 2009a.

Planta Daninha, Viçosa-MG, v. 30, n. 1, p. 193-200, 2012
D’ANTONINO, L. et al. Lixiviação do picloram em Argissolo Vermelho-Amarelo e Latossolo Vermelho-Amarelo com diferentes valores de pH. Planta Daninha, v. 27, n. 3, p. 589-600, 2009b.

FERRI, M. V. W., VIDAL, R. A., MEROTTO JR., A. FLECK, N. G. Atividade dos herbicidas flumetsulam e trifluralin em diferentes valores de $\mathrm{pH}$ e densidade do solo. Ciência Rural, v. 30, n. 1, p. 11-14, 2000.

GUIMARÃES, P. T. G. et al. Cafeeiro. In: COMISSÃO DE FERTILIDADE DO SOLO DO ESTADO DE MINAS

GERAIS. Recomendações para uso de corretivos e fertilizantes em Minas Gerais: 5a aproximação. Viçosa, MG: 1999. p. 289-302.

KELLEY, K. B. et al. Soybean response to plant growth regulator herbicides is affected by other postemergence herbicides. Weed Sci., v. 53, n. 1, p. 101-112, 2005.

LOCKE, M. A.; BRYSON, C. T. Herbicide-soil interactions in reduced tillage and plant residue management systems. Weed Sci., v. 45, n. 2, p. 307-320, 1997.

MERSIE, W.; FOY, C. L. Phytotoxicity and adsorption of chlorsulfuron as affected by soil properties. Weed Sci., v. 33, n. 4, p. 564-568, 1985.

OLIVEIRA JR. R. S. et al. Sorption and leaching potential of herbicides in brazilian soils. Weed Res., v. 41, n. 2, p. 97-110, 2001.

PANG, L. P. et al. Simulation of picloram, atrazine and simazine leaching through two New Zealand soils and into groundwater using HYDRUS-2D. J. Contam. Hydrol., v. 44, n. 1, p. 19-46, 2000.

PEMADASA, M. A.; JEYASEELAN, K. Some effects of three herbicidal auxins on stomatal movements. New Phytol., v. 77, n. 3, p. 569-573, 1976.

RODRIGUES, B. N.; ALMEIDA, F. S. Guia de herbicidas. 5.ed. Londrina: IAPAR, 2005. 591 p.

SANTOS, M. V. et al. Eficácia e persistência no solo de herbicidas utilizados em pastagem. Planta Daninha, v. 24, n. 2, p. 391-398, 2006.

SILVA, A. A. et al. Herbicidas: comportamento no solo. In: SILVA, A. A.; SILVA, J. F. Ed. Tópicos em manejo de plantas daninhas. Viçosa, MG: Universidade Federal de Viçosa, 2007. p. 189-248.

SOUZA, M. D. et al. Adsorção e lixiviação de tebuthiuron em três tipos de solo. R. Bras. Ci. Solo, v. 25, n. 4, p. 10531061, 2001

THILL, D. Growth regulator herbicides. In: WELLER, S. C. et al. (Eds.) Herbicide action course. West Lafayette: Purdue University, 2003. p. 267-291. 